\title{
Influence of the COVID-19 Coronavirus Distribution on the Organization of Higher Education in Russia
}

\author{
Tatiana A. Yakovleva ${ }^{1}$, Anzhelina A. Koriakina ${ }^{2, *}$ \\ ${ }^{1}$ Faculty of Law, M. K. Ammosov North-Eastern Federal University, Russia \\ ${ }^{2}$ Institute of Foreign Philology and Regional Studies, M. K. Ammosov North-Eastern Federal University, Russia
}

Received September 3, 2020; Revised October 27, 2020; Accepted November 11, 2020

\begin{abstract}
Cite This Paper in the following Citation Styles
(a): [1] Tatiana A. Yakovleva, Anzhelina A. Koriakina, "Influence of the COVID-19 Coronavirus Distribution on the Organization of Higher Education in Russia," Universal Journal of Educational Research, Vol. 8, No. 12, pp. 6745 - 6750, 2020. DOI: 10.13189/ujer.2020.081239.
\end{abstract}

(b): Tatiana A. Yakovleva, Anzhelina A. Koriakina (2020). Influence of the COVID-19 Coronavirus Distribution on the Organization of Higher Education in Russia. Universal Journal of Educational Research, 8(12), 6745 - 6750. DOI: 10.13189/ujer.2020.081239.

Copyright $\odot 2020$ by authors, all rights reserved. Authors agree that this article remains permanently open access under the terms of the Creative Commons Attribution License 4.0 International License

\begin{abstract}
The pandemic of the coronavirus infection COVID-19 has made great adjustments in all aspects of the life in the global community, and education has not been left aside. The purpose of the present article is to reveal the psychological and pedagogical consequences of the spread of the coronavirus on the organization of higher education in Russia, the readiness of participants of the educational process to switch to distance learning. The article shows the results of a survey of students of Russian universities on the organization of distance learning in the context of the coronavirus pandemic. A comparative analysis of the possibilities and advantages of traditional and distance learning, of the distance learning methods used by university teachers, as well as the psychological and pedagogical readiness of participants of the educational process of Russian universities for the transition from classroom to on-line and off-line training is carried. The authors conclude that modern living conditions require adjustments, revision and rethinking of the educational process, partial transition to distance learning, which in the future may become prevalent. Today, the educational environment is not yet ready to switch to full distance learning, due to the lack of new and proven distance learning methods aimed at developing practical skills and abilities. Nowadays, there are no research results regarding the attitude of university students, especially Russian, to the urgent transition to distance learning in the context of the coronavirus pandemic. The present study is a pioneer in this field of study.
\end{abstract}

Keywords Higher Education, Coronavirus Infection, Educational Environment, Distance Learning, On-line Training, Off-line Training, Distance Learning Methods

\section{Introduction}

The pandemic of the coronavirus infection COVID-19 has made great adjustments in all aspects of the life in the global community, and education has not been left aside. According to UNESCO, on April 20, 2020, the closure of educational institutions affected the educational interests of 1575270054 or $91.3 \%$ of students around the world, and this number includes university students [1].

There are a lot of scientific studies on the closure of educational institutions to minimize the spread of infectious diseases in different locations [2-4]. Practically all universities around the world have canceled all their events such as conferences, seminars, etc. to prevent the spread of the COVID-19 pandemic. Universities quickly switched from full-time education to online mode for all courses and programs [5-7].

A large analytical material on the insufficient readiness of the complete transition of the educational process of the general education system to the distance mode was prepared by the staff of the Russian Academy of National Economy and Public Administration under the President of the Russian Federation and the Department of Regional 
and International Cooperation of the Accounts Chamber of the Russian Federation $[8,9]$. The authors point out a number of problems associated not only with the technical possibilities of distance learning, but also with the lack of practical experience of online learning and of the psychological readiness of parents and students for distance learning, etc.

Most of the studies on the impact of the spread of the Covid-19 coronavirus on the organization of distance learning have affected the general education. We must pay tribute to the Ministry of Science and Higher Education of the Russian Federation, which made an immediate decision to transfer higher education to distance learning.

Today, there are no research results regarding the attitude of university students to the urgent transition to distance learning in the context of the coronavirus pandemic.

How did students react to the transition from traditional (classroom) to distance learning? What difficulties did students face in learning? How prepared were teachers for such changes when organizing the transition of the educational process from classroom to distance learning? What distance learning methods occurred to become the most effective in mastering training courses and have been used by teachers? In search of an answer to these questions, as well as in order to study and evaluate the experience of distance learning in Russia, the North-Eastern Federal University conducted a survey of students of Russian universities. The answers to these questions generally demonstrate the psychological and pedagogical consequences of the spread of the coronavirus infection COVID-19 pandemic on the organization of higher education in Russia, the readiness of participants of the educational process to switch to distance learning.

\section{Research Methodology}

This study was conducted using the following methods:

- analysis of Russian and foreign literature on the research topic, as a result of which modern methods of distance and interactive learning have been generalized, as well as their application in universities in the context of traditional education and transition to distance learning, in connection with the coronavirus pandemic;

- $\quad$ a survey (questioning) of university students in order to study and evaluate the experience of distance learning in Russia in modern conditions;

- quantitative method of analysis of survey data, the results of which were subjected to mathematical analysis and statistical processing. Calculations of the quantitative characteristics of the survey were carried out by the method of mathematical statistics and quantitative methods of measuring values;

- a comparative analysis of the results of the survey, that made it possible to identify the most accessible methods of distance learning, the use of electronic didactic teaching materials by teachers and their preference by students, aspects of the psychological and pedagogical readiness of participants of the educational relations to on-line and off-line learning in the context of a quick transition from traditional (classroom) to distance learning.

120 full-time (95\%) and part-time (5\%) students of undergraduate and graduate programs from 11 Russian universities took part in the survey. (Irkutsk State Medical University (Irkutsk), Moscow Automobile and Road Construction State Technical University (Moscow), Lomonosov Moscow State University (Moscow), Mirny Polytechnic Institute (Mirny), St. Petersburg State University of Architecture and Civil Engineering (St. Petersburg), St. Petersburg State University of Information Technologies, mechanics and optics (St. Petersburg), St. Petersburg State University (St. Petersburg), St. Petersburg State University of Economics (St. Petersburg), St. Petersburg Institute of the All-Russian State University of Justice (RPA Ministry of Justice of Russia ) (St. Petersburg), North-Western State Medical University named after I.I. Mechnikov (St. Petersburg), North-Eastern Federal University named after M.K. Ammosov (Yakutsk). The age of students ranged from 17 to 46 years old, of which $68.3 \%$ were women and $37.1 \%$ were men. The survey was conducted from July 16 to August 16, 2020

The questionnaire consisted of 12 multiple-choice questions and one open-ended question. It should be noted that each question had an open answer line.

\section{Research Results}

In the context of the coronavirus pandemic, $99.2 \%$ of the above universities in Russia switched to distance learning (on-line and off-line), $0.8 \%$ continued their traditional form of education (classroom).

To the question, "How do you assess the transition from traditional (classroom) training to distance and on-line training?" $55 \%$ of the students who took part in the survey noted that there were both positive and negative aspects, $34.2 \%$ reacted positively, $9.2 \%$ negatively, $1.6 \%$ found it difficult to answer.

For distance learning, teachers used video conference platforms for on-line classes: ZOOM, DISCORD, SKYPE, INSTAGRAM, GOOGLE-MEETS. Off-line classes were mainly conducted using SEDO Moodle, SEDO Blackboard Learn, WhatsApp, e-mail. It follows from this that not all Russian universities are provided with special electronic educational systems. More often, publicly accessible platforms on the Internet and social networks were used, intended for communication of a wide range of people.

Teaching of educational material was carried out using video lectures $(77.5 \%)$, presentation of theoretical material (79.2\%), block diagrams, maps, tables, figures, 
illustrations of a lesson on the certain topic (52.5\%), presentations of practical and laboratory lessons (40\%), video-practical and laboratory lessons $(25.8 \%)$, electronic lectures $(59.2 \%)$, collections of educational tasks and exercises $(65 \%)$. Students noted that the tasks were given on for several days, and only then they were sent to teachers for checking.

It seems interesting that when studying the topic, students used educational materials developed by teachers $(81.7 \%)$, materials that are freely available on the Internet $(71.7 \%)$, educational and scientific literature from various sources $(60.8 \%)$. Educational and scientific literature from the electronic library systems fund of the university was noted by only $42.5 \%$ of the students who took part in the survey. $75.8 \%$ of surveyed students assessed the use of didactic teaching materials developed by a teacher of their university positively, $9.2 \%$ - negatively, due to the fact that the materials are not understandable without additional clarification from a teacher. $8.3 \%$ of such students believed that the materials were not needed since on the Internet they could find any material to clarify the topic, $7.5 \%$ found it difficult to answer. $6.7 \%$ of surveyed students chose the answer: I do not estimate them in any way, because they were not useful in the assimilation of educational material; $0.8 \%$ remained neutral.

When assessing the sufficiency of the educational process with didactic materials, $42.5 \%$ of students noted the answer option "good, but not for all topics and subjects they were developed and available"; $32.5 \%$ chose the answer "excellent, because were developed and available on all topics and subjects of the course and were useful in mastering the topic, course "; $22.5 \%$ preferred the materials, necessary to understand the topic and the course, posted on the Internet; $16.7 \%$ used didactic materials developed by teachers of their own university and other universities on the recommendation of the lead teacher of the course. $6.7 \%$ of surveyed students considered that the materials were not needed, $3.3 \%$ found it difficult to answer.

$66.7 \%$ of students noted an increase in the load of independent study of the material during distance learning, $13.3 \%$ did not notice the difference in independent study load when switching from traditional to distance learning, $10 \%$ thought that the volume of independent work did not change and remained the same, $7.5 \%$ spoke about reducing the teaching load, $2.5 \%$ found it difficult to answer.

To the question "How do you yourself assess the assimilation of educational material in distance learning" an equal number of answers scored the following options: "I learned well, independent study of the material does not cause difficulties and stimulates learning" and "I learned well, but there is not enough live communication with teachers and classmates" $(25.8 \%$ for each of the answers given above). $15.8 \%$ of students believed that they had mastered it perfectly, did not feel the difference between traditional and distance learning, $13.3 \%$ assessed the assimilation of the material satisfactorily, there were difficulties in the independent study of the material, $12.5 \%$ learned it well, some questions caused difficulties in understanding and mastering the educational material. Only $4.1 \%$ of the students admitted that they had not mastered the educational material, because distance learning did not provide the same knowledge as in traditional education $(2.5 \%)$, and there was a lack of practical skills in distance theoretical education (1.6\%).

In general, students reacted positively $(53.4 \%)$ or neutral $(30 \%)$ to distance learning, and only $15 \%$ - negatively. One of surveyed students $(0,8 \%)$ noted that only currently he had a negative attitude, but in the future, with a high-quality organization of the educational process by the university, he would continue distance learning. The rest found it difficult to answer.

An interesting fact is that students in the future would choose a combination of classroom and distance learning $(41.7 \%), 40 \%$ spoke for full distance learning and only $16.7 \%$ were for traditional (classroom) training. 1.6\% of students found it difficult to answer.

The last question of the questionnaire consisted of open-ended questions: What positive and negative points did you highlight in distance learning? What are your wishes and recommendations for improving distance learning in Russian universities?

Among the positive aspects, students mainly noted the saving of time on the road, food, convenience in the distribution of their time and free study schedule, more free time, living at home, not in a dormitory, possibility of getting an education without leaving home in a comfortable environment, i.e. aspects not affecting the educational process itself. The only positive moment in the organization of the educational process, by the opinion of students, is the ability to view the lecture material several times. As for the negative aspects, they, for the most part, affect the organization of distance learning: the lack of technical capabilities for distance learning (power outages, lack of high-quality Internet connection, etc.), difficulties in assimilating educational material, increasing the load of independent study of educational material, lack of communication with teachers in terms of clarification of educational material, lack of more informative visual didactic materials, lack of application practice. In addition, students noted the difficulties of transition to distance learning by teachers of the older generation, i.e. lack of practical experience of on-line training. Young teachers in a short time more successfully adapted to teaching on-line.

\section{Discussion of the Results}

As noted in the scientific literature, distance learning is carried out through Internet technologies, in which a student is removed from a teacher [10] and is mainly based on self-study using an electronic course [11], extracurricular. The advantages of this form of education 
are the availability of all educational materials regardless of place of residence, health status, financial capabilities, as well as the ability to create individual educational trajectories [12, 13, 14, 15].

Despite the positive aspects of distance learning, the literature also highlights negative aspects, such as the lack of socio-psychological contact and motivation, because in the group the educational process is stimulated by the presence of unspoken rivalry between students, self-expression and social interaction of a student not only with a teacher, but also with classmates and friends [10]. On the other hand, in the absence of socio-psychological contact, some authors see a positive side - the disappearance of the psychological barrier in communication [11].

In the scientific literature, there is an opinion that distance learning has not been widely used in Russia due to the lack of an assessment of the quality and advantages of such training; it is partially used in correspondence courses $[13,16]$. The same can be said about some other countries' experience in distance teaching where assessment aspect is often underdeveloped [17].

The disadvantages of distance learning should be supplemented with the difficulties of using interactive teaching methods, which are aimed at developing practical skills for future professional activity in the absence of specialized educational e-learning systems. Today, most of the interactive teaching methods, educational technologies have been developed and aimed at conducting certain types of classes (lessons), there is no experience in conducting a full course in electronic and distance formats.

\section{Conclusions}

Despite the presence of a large number of domestic and foreign scientific and methodological developments in distance learning and interactive teaching methods, the educational system in Russia was not ready for a full transition to distance learning. The results of the survey of students of Russian universities reveal the disadvantages of the first forced and quick transition to full distance learning:

1) distance learning, conducted in some Russian universities during the coronavirus pandemic, showed that teaching was more focused on self-education, on the study of theoretical material, i.e. acquiring knowledge;

2) didactic materials developed for classroom lessons, where a teacher explains and comments on the educational material, are not suitable for distance off-line learning, because students had to look for additional information to master the topic and consult with teachers;

3) the absence of a methodology for using electronic seminars in the educational process excluded the use of interactive forms of classes aimed at the formation of professional competencies (skills and abilities) and, therefore, caused the problem of implementing the requirements of the Federal State Educational Standard of Higher Education;

4) the lack of the ability to track and control the independence of the task completing on the part of students in distance learning does not ensure the objectivity of the assessment of knowledge, skills and abilities acquired by students at a distance;

5) distant education put urban and rural students in an unequal position, due to the lack of uninterrupted Internet connection in rural settlements. Many rural students were unable to attend on-line classes;

6) the lack of provision of many universities with special electronic educational systems that make it possible to transfer the educational process to distance e-learning, has increased the use of publicly available communication facilities not intended for training. This, in turn, affected the quality of teaching and the quality of students' perception of the educational material.

From personal experience, we would like to note that not all students conscientiously and responsibly did their independent work. We were faced with the fact that some students sent their works copied from the Internet, passed completed works to each other, i.e. they worked not for gaining knowledge, but for the "tick" - the task is "completed and sent."

Thus, not all e-learning methods in modern conditions are aimed at the formation of practical skills. Rethinking and developing new approaches to teaching educational material in on-line and off-line learning is required, including interactive methods that have remained out of use.

Specific recommendations to improve the effectiveness of the transition to distance learning are as follows.

The most suitable, both from the point of view of the possibility of application, and from the point of view of improving modern educational technologies in the conditions of distance learning, will be the widespread use of video presentations of master classes. Currently, this technology is more often used as a form of professional development of teachers, demonstration of pedagogical experience [18].

A change in the relationship between teachers and students should also follow, as modern approaches of distance learning should be aimed at independent study of some issues of the subject area. In this aspect, the most acceptable, in our opinion, is the project-based teaching method.

The transition to partial or complete distance education is possible only in the case of psychological readiness of the participants of the educational process: the ability to concentrate and understand the information through electronic media. In direct communication, a modern person uses all the senses (visual, auditory, tactile, 
gustatory, and olfactory). In the case of distance learning, only two types of senses work - auditory and visual. Therefore, a person should become an audio-visualist, otherwise distance learning will not achieve its goal.

The researchers claim that large groups of students in Internet courses can limit the lecturer's communication and interaction with students, which can, in turn, lead to one-way teaching, few opportunities for discussion and critical questions. Therefore, such factors like group size, teaching in real time and communicating through video conferencing with chat are important to the quality of online teaching [19].

Teacher's rethinking of his/her roles and the transit to the position of a consultant and moderator is very important. Continuing education programs and reskilling in the field of e-Competence for teachers are necessary. The most active teachers should share their experience and knowledge through social networks and special webinars. A program for the development of digital tools and digital content for organizing online format practical classes is in demand.

From the part of universities: preparation of teacher's guidelines, creation of special sites or sections of official sites to inform and help teachers in the current mode, programs of methodological support for teachers on their own base and the opportunity to take external courses free of charge, as well as the use of the appropriate websites of leading universities. Rethinking of digital infrastructure of universities (cloud systems of organization and support of educational process, development of wireless high-speed networks access to the Internet) is necessary.

Removing barriers to flexible and individualized educational trajectories and allowing students to score online courses from other universities in their curriculum are in huge demand. Development of self-organization and self-learning skills in students, new forms of independent work, and special adaptation courses for mastering new digital educational tools activities are very important at this stage.

\section{REFERENCES}

[1] UNESCO website COVID-19 Educational Disruption and Response - URL: https://en.unesco.org/covid19/educationre sponse

[2] Kawano S, Kakehashi M. Substantial impact of school closure on the transmission dynamics during the pandemic flu H1N1-2009 in Oita, Japan. PLoS One. 2015. https://doi.org/10.1371/journal.pone.0144839

[3] Luca GD, Kerckhove KV, Coletti P, Poletto C, Bossuyt N, Hens N, Colizza V. The impact of regular school closure on seasonal influenza epidemics: a data-driven spatial transmission model for Belgium. BMC Infect Dis. 2018. https://doi.org/10.1186/s12879-017-2934-3

[4] Wheeler CC, Erhart LM, Jehn ML. Effect of school closure on the incidence of influenza among school-age children in Arizona. Public Health Rep. Vol.125 (6), pp. 851-859, 2010

[5] Gewin V. Five tips for moving teaching online as COVID-19 takes hold. Nature, 2020 https://doi.org/10.1038/d41586-020-00896-7

[6] Kaup S. Jain R, Shivalli S., Pandey S., Kaup S. Sustaining academics during COVID-19 pandemic: The role of online teaching-learning. Indian J Ophthalmol, Jun;68(6):1220-12 21, 2020 Doi: 10.4103/ijo.IJO_1241_20.

[7] Schneider S., Council M. Distance learning in the era of COVID-19. Archives of Dermatological Research https://doi.org/10.1007/s00403-020-02088-9

[8] Tarasova N.V. How does the transfer of the educational process to a distance mode affect educational results - URL: https://firo.ranepa.ru/novosti/105-monitoring-obrazovaniyana-karantine/803-tarasova-ekspertiza\#_Toc39055690

[9] Digest Coronavirus epidemic: impact on education. Department of Regional and International Cooperation of the Accounts Chamber of the Russian Federation, 2020, p.12 https://ach.gov.ru/upload/pdf/Covid-19-edu.pdf

[10] Filippova I.Ya. Review of modern methods of distance education. Scientific journal "Video Science", №3 (3), Volume 1, pp. 13-18, 2016

[11] Ponachugin A. V. Organization of interactive interaction in e-learning. Bulletin of Minin University, No. 4, 2017

[12] Dupuy A., Izhutkin V., Pickl S., Tschiedel R. Judgment Based Analysis via an Interactive Learning Software for Modern Operations Research Education and Training. Proceedings of the International Conference for Operations Research (Selected Papers). Berlin, Heidelberg: Springer Verlag, pp. 623-628, 2011.

[13] Valeev E., Valeeva R., Fakhrutdinova A. Prospects for the Use of Foreign Experience of Distance Learning. The Proceedings of 6th World Conference on educational Sciences Procedia - Social and Behavioral Sciences, Vol. 191, pp. 1909-1912, 2015.

[14] Selira Kotoua. The Growing of Online Education in Sub Saharan Africa: Case Study Ghana. Procedia - Social and Behavioral Sciences, Volume 191, 2, pp. 2406-2411, 2015

[15] Filiz Kantek. Distance Education in Nursing in Turkey. Procedia - Social and Behavioral Sciences, Volume 116, pp. 639-64321, 2014

[16] Ayupova L.I. Distance learning and Russian realities. Electronic scientific and educational Bulletin "Health and education in the XXI century, Vol. 18 (9), pp. 10-14, 2016

[17] Timmis S, Broadfoot P, Sutherland R, Oldfield A. Rethinking assessment in a digital age: opportunities, challenges and risks. British Educational Research Journal, Vol. 42(3), pp. 454-476, 2016

[18] Safina R.N. The role and place of the master class in improving the research and methodological potential of university teachers. Bulletin of the Samara Scientific Center of the Russian Academy of Sciences, vol. 13, № 2, pp. 54-56, 2011.

[19] Monica J. Lervik, Tone Vold, Stig Holen, "Conditions for Cooperating and Dialogue through the Utilization of 
Technology in Online Education," Universal Journal of Educational Research, Vol. 6, No. 10, pp. 2352 - 2363, 2018.
DOI: 10.13189/ujer.2018.061034. 